\title{
Die Psalms - Woord en antwoord1
}

J H Coetzee

\begin{abstract}
\end{abstract}
The psalms - Word and reply

The psalms of the Old Testament have always been and still are a unique means of communication between the believer and God. The nature and functioning of the psalms in the past as well as the present are explored and principles for their meaningful usage by the modern day church formulated.

\section{INLEIDING}

Die titel van hierdie artikel impliseer 'n grondliggende vraag, naamlik: "Wat is die psalms en watter rol speel hulle in die lewe van die gelowige lidmaat van die kerk?" Vir die meeste gelowiges is die psalms tot 'n groot mate 'n vanselfsprekendheid in hul geloofslewe. Hulle is daar - in ons Bybels en liedereboeke - en ons gebruik hulle gereeld.

'n Baie algemene standpunt as antwoord op bogenoemde vraag is vandag dat die psalms die gelowige mens se antwoord of reaksie op die spreke van God is 2 . Myns insiens moet die psalms wyer as dit gedefinieer word. Die psalms is enersyds 'n verwoording van die gelowige mens(e) se reaksie(s) op die positief of negatief ervaarde aansprake wat God en sy skepping van binne en van buite af op die psalmdigters gemaak het. Hierdie reaksie word as lief en/of leed in omvattende sin geestelik (innerlik) en fisies (sang, ritme, musiekinstrumente, gebed en gebedshouding, ens) primêr tot God gerig. Wanneer daar samesang en gesamentlike gebed uit die psalms plaasvind, of in die geval van'n psalm met eksplisiete onderrigdoelwitte, het die gebruik daarvan ook 'n interpersoonlike effek van samehorigheid in aanbidding/onderrig op die gelowiges wat betrokke is. Andersyds is die psalms as deel van God se geskrewe Woord die kommunikasiemiddel waardeur Hy aan die mens leiding wil gee oor die inhoud en aard van ons reaksie ${ }^{3}$. Die sinvolle gebruik van die psalms impliseer altyd of 'n drieledige of 'n tweeledige verhouding, naamlik dié tussen God, die gelowige en sy medemens, of tussen die gelowige alleen en God. Met hierdie meer omvattende uitgangspunt in gedagte kan ons dus van die psalms praat in terme van "Woord" (van God) en "antwoord" (van die mens). In die dialoog kan dit egter ook word "woord" (van die mens) en "Antwoord" (van God).

Die psalms, wat aanvanklik die liedere van Israel was en later ook die bron van die kerk se liedereskat uitgemaak het, is die boek in die Ou Testament wat seker die meeste gebruik word ${ }^{4}$ op 'n verskeidenheid van terreine van die geestelike lewe. In die kerk is die psalms deur die eeuc heen betrokke by die liturgie (liederebundels), die pastoraat, die individuele godsdiensbeoefening en die prediking 5 . Hierdie feit wil vir ons in 'n neutedop iets sê oor die aard en funksie van die psalms, naamlik dat dit universele geestelike waarde het en dat dit die intieme verhouding tussen die individuele gelowige en die gelowige binne korporatiewe verband en God wil versterk. 
Wanneer daar vervolgens na die aard van die psalms gekyk word, sluit dit vir die doeleindes van hierdie bespreking die moontlike ontstaansagtergrond, die vorm en literêre styl, asook die psalms en musiek in. Ten opsigte van die funksie word u aandag gevra vir die verskillende gebruike van die psalms in die verlede en vandag, asook vir sekere veronderstelde beginsels wat toegepas behoort te word vir die sinvolle gebruik daarvan.

\section{DIE AARD VAN DIE PSALMS}

\subsection{Die ontstaansagtergrond}

Die woord "psalm" is van Griekse oorsprong (psalmbs) en beteken "tokkel" of "pluk". Die ekwivalente Hebreeuse terme is mizmor en SIr wat dui op sang wat op snaarinstrumente begelei word. Die Hebreeuse naam vir die Psalmbundel in die Bybel is egter $t^{c} /$ hillim, wat met "lofprysinge" vertaal kan word, en wat duidelik heenwys na die gebruik van die psalms in die tempeldiens.

Alhoewel daar' $n$ verskeidenheid van standpunte is, stem die meeste psalmnavorsers saam dat die Psalmbundel in sy geheel oor' $n$ tydperk van ten minste agt eeue ontwikkel het tot in sy huidige finale vorm. Sommige psalms dateer uit die voor-ballingskapstyd, byvoorbeeld die koningspsalms (Ps $2 ; 20 ; 21 ; 72 ; 110)$. Ander dateer moontlik uit die ballingskapstyd self (Ps 60; 74). Ná die ballingskap het daar ook psalms ontstaan (bv Ps 126; 137). Wanneer die verskillende versamelings, soos byvoorbeeld die Bedevaartsliedere, die Koragitiese- en Asafbundels en die Dawidiese versameling ontstaan het, is, net soos in baie individuele psalms se geval, moeilik om presies vas te stel. Waarskynlik is daar in koning Hiskia se tyd (721-693 vC) gepoog om liedere te versamel (2 Kron 29:30).

Die psalmbundel bestaan uit 'n verskeidenheid van psalms wat op die ong af lyk of dit willekeurig gerangskik is. Trouens, omdat 'n mens dikwels net met individuele psalms werk, kom jy nie eintlik agter dat daar enige mate van rangskikking is nie, behalwe by die sogenaamde Bedevaartsliedere. Wanneer die psalmbundel in sy geheel gelees word, merk mens op dat daar byna op 'n refreinagtige wyse by die volgende psalms die lof van die Here besing word: $41: 14 ; 72: 18-19$; $89: 53 ; 106: 48 ; 150$. Met hierdie doksologieë word die psalmbundel intern afgebaken om in die geheel vyf sogenaamde "boeke" of versamelings te vorm, te wete 1$41 ; 42-72 ; 73-89 ; 90-106 ; 107-150$. Die aaneenskakeling van hierdie vyf bundels het waarskynlik eers ná die terugkeer uit die Babiloniese ballingskap plaasgevind, wat aan die psalmbundel die naam "Gesangeboek van die Tweede Tempel" besorg het ${ }^{6}$. Die finale redaksionele verwerking van die psalmbundel in die Hebreeuse Bybel soos ons dit vandag ken, het op die laaste in die jaar $200 \mathrm{vC}$ plaasgevind?

Met betrekking tot die ontstaansagtergrond van die psalms is daar uiteenlopende menings wat varieer tussen die volgende twee hoofdenkrigtings of pole:

(a) Die psalms is gebore uit werklike belewenisse van individue of die volk en is later in die bundel opgeneem as liedere wat vir die kultus gebruik kan word. In hicrdie geval is die outeur van so 'n psalm die individu wie se belewenisse beskryf word. Die inhoud van die oorspronklike psalm sou dan deur die tempelpersoneel aangepas word vir kultiese gebruik. 
(b) 'n Ander standpunt is dat al die psalms, of dan die grootste meerderheid, deur die kultuspersoneel vir die kultus geskryf is. Praktiese lewensituasies is dan in die oog gehou by die skryf daarvan. Om die algemene gebruik daarvan te verseker, is die inhoud redelik vaag en algemeen voorgestel, byvoorbeeld die vyande wat byna nooit by die naam genoem word nie en noodsituasies wat beeldryk, maar baie vaag beskryf word. Dit is ook opvallend dat die psalms dikwels "formuletaal" bevat wat redelik geyk was.

$\mathrm{Na}$ my mening toon die verskeidenheid van psalms vir ons dat ons hulle ontstaansagtergrond nie in net een van hierdie twee moontlikhede moet gaan soek nie. Hoewel dit vandag baie moeilik is om hierdie agtergronde presies vas te stel, moet ons erken dat sowel individuele (en korporatiewe) gebeurtenisse as direkte kultiese behoeftes aanleiding tot die ontstaan van die psalms gegee het. Ons kennis van die genres en die historiese en sosiale ontstaansagtergrond van die psalms kan ons wel help met die interpretasie daarvan, maar daar is ook ander bykomende elemente soos die sintaktiese, semantiese, stilistiese en resepsie-teoretiese elemente wat almal saam meehelp om 'n psalm te verstaan. Dit is dus nodig dat psalmdeskundiges hulle sal wy aan 'n gebalanseerde benadering waar aan al hierdie fasette van die navorsing aandag gegee word.

Wat die opskrifte van die psalms betref is daar redelike eenstemmigheid onder geleerdes dat dit latere byvoegings is en dat dit ons nie werklik help om die psalms se inhoud beter te verstaan nie. Dit sluit egter nie uit dat ons kennis hiervan in die toekoms ander insigte sal kan bring nie (vergelyk byvoorbeeld die Skandinawiese geleerdes wat die opskrifte vanuit die kultus wil verklaar). Die opskrifte bestaan gedeeltelik uit musikale en gedeeltelik uit historiese aanduidings.

Baie opskrifte bevat die name van persone soos Dawid, Salomo, Moses, die kinders van Korag en Asaf, Heman en Etan. Die Hebreeuse voorsetsel lc wat aan 'n naam verbind is (bv ledawid) kan beteken "aan Dawid", "van Dawid", "vir Dawid". Hierdie name dui dus nie noodwendig op outeurskap nie. Drie-en-sewentig psalms word aan Dawid se naam gekoppel: Pss 3-9; 11-32; 34-41; 51-65; 68-70; $86 ; 101 ; 103 ; 108-110 ; 122 ; 124 ; 131 ; 133 ; 138-145$; an Salomo: Ps 72 ; aan Moses: Ps 91; aan die Koragiete: Pss 42; 44-49; 84-85; 87-88; aan die Asafiete: Pss 50; 73-83; aan Heman: Ps 88; aan Etan: Ps 89. Hieruit kan afgelei word dat daar verskillende versamelings van psalms ontstaan het wat in die psalmbundel opgeneem is. Verder is dit duidelik dat daar mense was wat op een of ander manier 'n leidende rol gespeel het binne die tradisies van die verskillende versamelings en die musiek, vandaar die verbintenis van hul name met die psalms.

In die psalmopskrifte kom daar 'n verskeidenheid van tegniese terme voor, sommige waarvan die betekenis nie duidelik is nie. Sekere van die terme dui op die "aard" van die psalms, wat nie in terme van ons genre-indelings as "soorte" verstaan moet word nie. Aard dui waarskynlik op die musikale voordrag ${ }^{8}$. Voorbeelde van sulke tegniese terme is: "vir die koorleier" (Ps 109); "op die wysie van..." (45); "met snarespel" (4); "met fluitspel" (5); "met snarespel, met basstem" (6). Hierdie tegniese terme kan ingedeel word in versamelingsbegrippe, musikale vakuitdrukkings, kulties-liturgiese aanwysings, melodieë en wyses van sing? 
Daar is reeds vroeër opgemerk dat daar 'n verskeidenheid van genres onder die psalms voorkom. Ons kan, deur die inhoud van elke psalm noukeurig te lees en te ontleed, ook iets agterkom van die vorm waarin dit geskryf is. Die psalmnavorsing het aangetoon dat verskillende psalms se inhoud naastenby in dieselfde vorm "gegiet" is, wat dan 'n "soort" of "genre" of Gattung genoem word. Gewoonlik word gesê dat 'n bepaalde geykte genre ook 'n geykte ontstaansagtergrond het. So byvoorbeeld ontstaan 'n liefdeslied uit 'n liefdesituasie, of ' $n$ oorlogslied uit 'n oorlogsituasie, of 'n klaaglied uit 'n noodsituasie. Maar dan is daar ook psalms waarvan die genre nie so maklik vasgestel kan word nie, aangesien dit 'n "mengsel" van verskillende vorme bevat. Ons moet egter onthou dat elke psalm uniek is en dat sulke indelings nie rigied afgedwing kan word nie. Tog vertoon psalms van dieselfde vorm ooreenstemmende hoofkenmerke.

Vir die leser of gebruiker van die psalms is dit belangrik om iets hiervan te snap sodat die psalms sinvol gebruik kan word. Elke orrelis en predikant het byvoorbeeld die aanvoeling dat 'n klaaglied nie tydens 'n huweliksbevestiging gebruik behoort te word nie. Die vraag waarom dit dus eintlik gaan, is die funksie van ' $n$ psalm wat aan 'n bepaalde genre behoort. Hieraan word aandag gegee in afdeling 2 hieronder. Die volgende psalmgenres word gewoonlik onderskei10:

klaagliedere van die individu en van die volk (bv Ps $3 ; 5 ; 13 ; 22$ / 60; 74; 79; 80; 137);

vertrouensliedere van die individu en die volk (bv Ps 4; 11; 16; 23; 62; 131 / 46; 125; 129):

loflied/himne van die individu en van die volk (bv Ps $8 ; 19 ; 29 ; 33 ; 100 ; 104 ; 150$ ); danklied van die individu en van die volk (bv Ps $18 ; 30 ; 32 ; 34 ; 6 ; 7 ; 66 ; 67 ; 124$ ): liedere wat die Here se koningskap besing (bv Ps 93; 96; 97; 98; 99);

koningspsalms (bv Ps $2 ; 18 ; 20 ; 21 ; 45 ; 72 ; 89 ; 110$ );

oorwinningsliedere (bv Ps 46; 48; 66; 76; 118 );

wysheidspsalms (bv Ps 1 ; 32; 34; 37; 49; 112; 127; 128);

mengvorme (bv Ps 94; 119);

liturgieë (bv Ps $12 ; 60 ; 81 ; 85 ; 95$ );

geskiedenispsalms (bv Ps 78; 105; 106);

Sionspsalms (bv Ps 48; 76; 84; 87; 122).

Let op die groot verskeidenheid van vorme waaraan die verskillende psalms behoort, terwyl elke psalm ook nog sy eie inhoud het en op sigself uniek is. Die meeste psalms sorteer onder die klaag- en dankliedere. Hierdie verskeidenheid maák'die gebruiksmoontlikhede van die psalms deur die kerk baie wyd.

\subsection{Die literĉre styl en die inhoud van die psalms}

Die literêre styl van die psalms het 'n lang geskiedenis en kan teruggevoer word na die kultuur wat algemeen was aan die hele Nabye Ooste vanaf Mesopotamië tot by Egipte.

' $n$ Tipiese kenmerk van die Hebreeuse poësie is die parallelle gedagtegang wat in 'n versreël voorkom. Nog 'n kenmerk is dat die inhoud van die psalms direk verband hou met menslike belewenisse, hetsy van die individu of van die volk. Daarom word daar gevind dat die digter se benadering tot sy stof meestal baie persoonlik is. Die dikwels "ongewone" taalgebruik "is bedoel om die belewenisse en 
die private perspektief op die werklikheid te help verwoord"11.

Die psalms van die Ou Testament is basies saamgestel uit woorde, beelde en ritme ${ }^{12}$. Die digterlike woord makk gebruik van klankspel (bv alliterasie en assonansie) en 'n verskeidenheid van retoriese figure (bv trapperym - Ps 121). Rym, soos ons dit ken, kom nie eintlik in Hebreeus voor nie. Die digterlike beeld kan in 'n verskeidenheid literêre stylfigure voorkom (bv vergelyking - Ps 1:3; metafore; hiperbole). Die digterlike metrum is baie nou verbonde aan die ritme van die taal self ${ }^{13}$. Oosterse musiek ken nie so-iets soos bewuste slae of "tellings" in die Westerse sin nie. Daarom het dit ook nie metriese eenhede wat aan maatstrepe verbind kan word nie. In die Ooste ontbreek die harmoniese element in musiek en ritme kompenseer daarvoor. Daarom speel slaginstrumente so 'n groot rol in Oosterse musiek.

Wat die inhoud van die psalms aanbetref, noem ek net 'n paar teologiese temas wat in die psalmbundel aangetref word: die God van Israel - sy openbaring en verberging; die volk van God; die individu in verhouding tot God en sy medemens; die koning; vyandelike magte ${ }^{14}$. Hierdie temas is op 'n baie kunstige wyse in die psalms verwoord as deel van die gelowiges se dialoog met God en hul volksgenote.

\section{$1.4 \quad$ Psalms en musiek}

In die $\mathrm{Ou}$ Ooste is daar van die vroegste tye af selde musiekinstrumente sonder sang bespeel15. Dit sou sekerlik ook die situasie met die volk Israel gewees het. Tydens die aartsvaders en die rigters het vrye teuels aan emosie die melodieë en ritme gevorm ${ }^{16}$. Rituele gebruike asook die algemene nasionale bewussyn het die sang gestimuleer ${ }^{17}$. Dit was veral in die tyd van Dawid en Salomo toe tempelmusiek formeel vorm aangeneem het en ontwikkel is, dat die sangpatroon in Israel 'n nuwe koers ingeslaan het. Sendrey ${ }^{18}$ stel dit soos volg:

Poets and musicians vied with each other to enrich the sacred service with a splendorous artistic investiture. The endeavor to serve God in word and tone, to praise His glory with singing and playing, led to the creation of immortal' art works, the most outstanding of which is the Book of Psalms.

Netsoos die digkuns, is ook die tonale kuns by Israel gestimuleer en beïnvloed deur hul godsdiens. Daarom moet die psalms gesien word as liries-religieuse gedigte wat geleidelik vir rituele gebruik aangeneem is ${ }^{19}$.

In die twee Kroniekeboeke wat uit die na-ballingskapstyd dateer ${ }^{20}$ en wat waarskynlik deur levitiese sangers of musici geskryf is 21 , word daar met gedetailleerde besonderhede gereflekteer oor die musiek van die tempel in Dawid en Salomo se tyd. Sang is gedurende die Dawid/Salomo-era ontwikkel tot 'n kuns en is met poësie verbind. Musiek het ook van toe af 'n permanente plek in die seremonies van die tempel gehad (1 Kron 16:7,37; 2 Kron 8:14). Gedurende die vroeë tydperk van die tempel is sommige psalms oorspronklik geskep om onder begeleiding van musiek gesing te word deur die professionele levitiese sangers in sowel solo- as koorverband 22 .

Om 'n tempelsanger te kon wees, was die voorreg van die stam van Levi (1 Kron 6:16 ev). In 1 Kronieke 15:16-22 vind ons 'n hele lys van name van Leviete 
wat 'n verskeidenheid van musiekinstrumente bespeel het tydens die geleentheid waar die ark van die verbond na Jerusalem toe gebring is. Heman, Asaf en Etan, wie se name ook aan sekere psalms gekoppel word, was die orkes- en koorleiers wat die voorreg gehad het om die teken met die kopersimbale te gee wanneer die orkes en koor moes begin. Kenanja was die hoofleier van die hele orkes en koor. Die tempelmusici was van die begin af in 'n gilde georganiseer waarin almal gelyk was met dicselfde voorregte en dieselfde pligte (1 Kron 25:8). Weens die streng dissipline kon die koor en orkes tydens die inwyding van die tempel van Salomo'n perfekte "ensemble" vorm (2 Kron 5:12,13), wat deur God self beantwoord is toe die tempel met ' $n$ wolk gevul is, wat die magtige teenwoordigheid van die Here uitgebeeld het. Dit is onder andere 'n pragtige voorbeeld van die kommunikasie tussen God en sy volk deur middel van musiek en sang.

Met verlcop van tyd het die res van die gelowiges al meer aktief betrokke geraak, eers deur net enkel woorde tussenin te sing, en later deur hele verse (refreine) te sing. Hieruit het mettertyd beurtsang en antifonale sang ontstaan 23 . Daar moet egter nie gedink word aan melodieë wat in elke strofe herhaal word, soos ons dit vandag ken nie. In die vroegste tye van psalmsang was daar glad nie strofes soos ons dit $\mathrm{ken}$ nie $\mathrm{en}$ in die Hebreeus bestaan daar nie reëlmatige strofes nie 24 .

Met betrekking tot die latere Babiloniese ballingskapstyd is dit uit Psalm 137 duidelik dat dit vir die ballinge moeilik was om in die vreemde die Here te loof met hulle sang en instrumente. Dit wys hoe ' $n$ intieme verband daar tussen die gemoedstemming, die lied en die instrument was.

Ná die Babiloniese ballingskap het die musiek en sang nie opgehou voorbestaan nie (Esra 2:41,65.70; Neh 7:44,67). Gedurende hierdie tyd is die psalms nie meer net in die (herstelde) heiligdom gesing nie, maar word dit deur die hele gemeenskap gebruik vir toewyding en vertroosting. Nou het die psalms werklik algemene volksbesit vir die Iode geword.

Omdat die sangers telkens apart in die boek Nehemia genoem word, kan afgelei word dat hulle ' $n$ spesiale status in die hiërargie van die na-ballingskapse tempel beklee het. In die nuwe tempel wat ná die ballingskap gebou is, was Ussi uit die nageslag van Asaf verantwoordelik vir die musiek (Neh 11:22; 12:42). Die sangers het gedurende hierdie tyd vir hul diens 'n soort betaling ontvang wat meestal uit natuurlike produkte bestaan het wat deur die volk gebring is as offers (Neh 12:47; 13:5). Dit is in hierdie situasie wat die huidige vorm van die psalmbundel van die Ou Testament tot stand gekom het 25 .

Die geskiedenis toon aan dat Israel se kultuur nie gesentreer het rondom filosofie en formele estetiese kunste nie. Die beeldeverbod het daartoe bygedra dat hulle weg van dic beeldende kunste af eerder op die vlak van die emosionele kuns klem gelê het, hyvoorbeeld musiek en poësie. Die landskap wat hulle bewoon het, het 'n groot invloed hierop uitgeoefen. Joodse musiek en poësie is baic emosioneel. In plaas van die intellektuele aard van byvoorbeeld Griekse musiek, het die Jode musiek beleef as iets transendents, ' $n$ gawe van God. Musiek (en ek wil hierby ook die poësie insluit) het nooit vir hulle 'n wetenskap geword nie, maar dit was kuns in sy fundamentele manifestasie, hemelse genade, goddelike openbaring ${ }^{26}$. 


\section{$2.1 \quad$ Liturgiese funksie}

Netsoos by die Jode, was die liefde vir musiek en die beoefening daarvan ook van groot belang vir die christene van die ontstaan van die Christendom af. As mense van Joodse afkoms het die vroeë Christene op 'n baie natuurlike wyse voortgegaan om die liedere van die Joodse liturgie te gebruik. Dit was aanvanklik soos die vroeë sinagogale sing-sing lees van die psalms, asook sang gebaseer op Joodse "wysies" wat almal geken het. Die eerste Christene het immers hul eredienste in die tempel (Hand $2: 46,47 ; 3: 1 ; 5: 42 ; 21: 26 ; 22: 17 ; 24: 17,18$ ) of in die sinagoge gehou (Hand $22: 19 ; 26: 11)$. In die Nuwe Testament word die sing van psalms net op vier plekke genoem (1 Kor 14:26; Ef 5:19; Kol 3:16; Jak 5:13). Die liedereskat het mettertyd ontwikkel in 'n liturgie van "psalms, lofsange en ander geestelike liedere" (Ef 5:19; Kol 3:16). Volgens Sendrey27 verwys die "psalms" na die ou Joodse psalms, die "lofsange" na die Bybelse lofsange soos Eksodus 15, Rigters 5, Jesaja 38 en die "ander geestelike liedere" na meer vrye godsdienstige uitdrukkings van die geloof in sangvorm. Laasgenoemde kon of net woordelose sangklanke of liedere met inhoude wat aan die Bybel ontleen is, inhou.

Die vroeë kerkvaders maak dikwels melding van die sing van psalms deur die Christene, soos beoefen op die tradisionele Joodse wyse ${ }^{28}$. So het Augustinus (354-430 $\mathrm{nC}$ ) byvoorbeeld gesê dat lofliedere en psalms gesing moet word volgens die Oosterse (Joodse) gebruik. Hieronimus (ca 340-420 nC) het in 'n brief aan die nonne van St Paula klooster geskryf dat daar geen suster mag bly as sy nie die psalms ken nie 29 . Verder is daar baie getuienis dat die psalms met volle oorgawe gesing is en selfs deur klein kindertjies geken is. Die kerkvaders het alle "nuwe liedere" wat teen die wese van die Joodse tradisie ingegaan het as ketters beskou ${ }^{30}$. Hulle geskrifte getuig daarvan dat die sing van psalms vir die nuwe Christene een van die belangrikste stimulante vir hul godsdienstige opheffing was en dat dit al die deelnemers met emosionele belewenis gevul het. Mense het hul soms so sterk ingeleef in die sing van psalms dat hulle aangegaan het met sing sonder woorde. Chrysostomus sê byvoorbeeld: "It is allowed to sing psalms without words, as long as the mind resounds within. For, we do not sing for men, but for God who can hear even our hearts and penetrate into the secrets of our soul"31.

Volgens die kerkvaders het die begeleiding deur instrumente nie die estetiese waarde van psalmsang geaffekteer nie. Die sang self bly die belangrikste element, selfs al word dit begelei. Begeleiding was dus vir hulle 'n ondergeskikte faktor. Daarom was die melodieë van die psalms waarskynlik eenvoudig sodat groot en klein dit maklik kon sing en dit deel van die daaglikse lewe kon wees. Die sing van psalms het verder ook gefunksioneer as 'n band tussen die individu en die godsdienstige gemeenskap. Die kerkvaders maak ook melding dat daar tydens huweliksbevestigings en begrafnisse psalms gesing is ${ }^{32}$.

Hierdie gegewens toon aan ons dat die psalms veral in die vroeë kerk baie populêr was en dat die sing daarvan aangemoedig is. In die Rooms-Katolieke Kerk het die kerkmusiek ontwikkel tot 'n alleenstaande verskynsel waaraan die gemeente nie meer deelgeneem het nie. Gedurende die reformatoriese tydperk het Luther weer die gemeentesang herstel. Beide Luther en Calvyn het psalms en ander liedere voorgestaan vir gemeentesang ${ }^{33}$. Calvyn het egter aan psalmbe-rymings 
rymings voorkeur gegee en so na as moontlik aan die Ou-Testamentiese teks gebly. In 1562 is die sogenaamde Geneefse Psalter voltooi met 125 melodieë vir die 150 psalms, gekomponeer deur Louis Bourgeois en Maître Pierre in die styl van die volkslied. Hierdie liedere het na baie lande toe versprei en gedien as ekumeniese bindmiddel ${ }^{34}$.

Baie gelowiges in Suid-Afrika ervaar vandag 'n stuk onvergenoegdheid met betrekking tot die psalms in die liederebundels van die drie Afrikaanse susterskerke. "Moeilike" melodieë en verouderde begrippe in die berymings word as redes voorgehou dat die psalms al minder gesing word tydens eredienste, wat nog te sê by ander spontane geleenthede. Die emosie van psalmsang as kommunikasiemiddel met God word deur faktore buite die psalms self doodgesmoor.

Vir ons om vandag die presiese woorde van die psalms te sing is natuurlik onmoontlik om drie redes:

(a) ons kan nie die Hebreeuse taal in ons eredienste sing nie;

(b) 'n letterlike vertaling is nie singbaar in normale Westerse musiekpraktyk nie;

(c) die Hebreeuse psalms bestaan nie uit reëlmatige strofes wat by ons melodieë kan inpas nie.

Reeds daarom word berymings van die psalms gemaak, waarmee natuurlik heelwat van die oorspronklike emosie en selfs inhoud van die psalms verlore gaan. Hierby moet ons ook onthou dat elke vertaling of beryming op sigself al interpretasie is, wat van moderne digter tot digter kan verskil. Daarom is dit baie belangrik dat kenners op die gebiede van die taal en teologie van die Ou Testament (en dalk ook Hebreeuse musiek), die moderne digkuns en taal, en die musiek almal saam betrek moet word by enige sinvolle projek om die psalms te berym en te toonset vir moderne gebruik. Ons is bewus van die lofwaardige poging wat in hierdie verband tans in ons land aan die gang is onder sommige Afrikaanse kerke.

Terwyl daar gewerk word in die rigting van 'n nuwe psalmberyming, is dit na my mening noodsaaklik om terselfdertyd te werk aan 'n handleiding vir predikante en musici vir die sinvolle gebruik van die psalms tydens die erediens asook vir alledaagse gebruik, byvoorbeeld by huweliksbevestigings, begrafnisse, huisgodsdiens, Bybelstudiegeleenthede, radio- en televisie-uitsendings. Indien daar parate inligting bestaan oor die soort psalm, die moontlike ontstaansituasie en moontlike gebruiksituasies, die kerngedagtes, die teologiese inhoud, die Nuwe-Testamentiese lig op moeilike Ou-Testamentiese temas soos die vervloeking van die vyande en die idee van die doderyk, ensovoorts, sal die predikant en pastor baie meer sinvol en effektief van die werklike inhoud en betekenis van die psalms gebruik kan maak. Die psalms sal dan ook baie meer funksioneel word vir ons tyd.

\subsection{Pastorale funksie}

Die psalms as deel van God se woord is by uitnemendheid geskik om aan die predikant se pastorale werk 'n besondere inhoud te gee. Omdat baie psalms 'n intiem-persoonlike karakter het, vind dit, as vertroostings-, bemoedigings-en dankbaarheidsverkondiging sterk aanklank by die individu in sy nood of in sy blydskap. Die psalms verwoord die gelowige mens se gevoelens en reaksies en daar 
is 'n openheid in die dialoogverhouding tot God wat nie altyd in die res van die Bybel gevind word nie. Sinvolle gebruik van die psalms deur die predikant in hierdie verband sal ook 'n verdieping van die sangbelewenis van 'n gemeente beïnvloed.

\section{$2.3 \quad$ Predikingsfunksie}

Op die vlak van die prediking verander die psalms nie ewe skielik van "mens-sewoord" na "God-se-woord" toe nie. Die psalms is en bly 'n kommunikasiemiddel tussen die mens en God en die mens en sy medemens. Die sinvolste preek wat ek tot nog toe uit die psalms beleef het, was waar die prediker dit reggekry het om die gemeente in die plek van die psalmdigter te laat staan en hulle as individue in dialoog met God gebring het. Dit was 'n illustrasie van die kernwaarheid dat die psalms ons altyd van 'n oor-God-praat-godsdiens na 'n met-God-praat-godsdiens toe moet lei35. Dit geld ook vir die prediking. Bogenoemde prediker het egter ook goed gebruik gemaak van die agtergrond, die vorm en inhoud, die poëtiese tegnieke van die psalm asook van die belewenis van die ontvangers van die boodskap. Sinvolle prediking uit die psalms sal ook die sangbelewenis van die gemeente stimuleer.

\subsection{Individuele godsdiensbeoefening as funksie}

Wie van ons het nog nie een of ander tyd baie vertroosting of stimulering van ons gemoedstemming uit die psalms gekry in ons persoonlike lewe nie? Reeds omdat so baie psalms die emosies van die gelowige verwoord, is hulle by uitnemendheid geskik vir persoonlike gebruik. Hoe meer ingelig die gewone psalmgebruiker oor die agtergrond, inhoud en betekenis van die psalms is, hoe meer diepte sal daaruit geput word om met God te kommunikeer.

\section{BEGINSELS VIR DIE GEBRUIK VAN DIE PSALMS}

\subsection{Konteks}

In al vier die toepassingsvelde van die psalms wat in afdeling 2 hierbo bespreek is, geld die basiese beginsel, naamlik: gebruik die psalms binne konteks. Maak erns met die psalm in sy geheel en vermy dit om 'n vers buite konteks te gebruik en toe te pas. Dit geld ook vir die liturgiese gebruik daarvan, naamlik wanneer die psalms as liedere tydens die erediens gesing word. Die gemeente behoort gereeld deur die leraar ingelig te word oor die breër agtergrond en teologiese inhoud van 'n psalm voordat een of meer strofes van die beryming gesing word. In hierdie verband sal 'n handleiding op die psalms, soos hierbo bepleit, 'n vinnige en voldoende naslaanwerk wees wat nie baie tyd in beslag hoef te neem nie.

\subsection{Gebruikmaking van die genre}

In aansluiting hierby gebeur dit dikwels dat 'n leraar die gemeente 'n "loflied" laat sing, maar dan 'n strofe uit 'n klaaglied opgee om gesing te word. Natuurlik bevat baie klaagliedere ook korter lofgedeeltes wat as lof gesing kan word. Hoeveel meer 
sinvol sal dit egter nie gedoen kan word indien ' $n$ leraar met behulp van 'n psalmhandleiding die genres van die liedere kan identifiseer en hulle implementeer vir die doel waarvoor hulle gedig is nie.

\subsection{Skakeling tussen leraar, orrelis en gemeente}

Om die sangbelewenis van die gemeente te bevorder, behoort daar voortdurende en sinvolle skakeling tussen die prediker en die musikus of musici van die gemeente te wees. Die prediker en musikus behoort vooraf te beplan hoe die betrokke liedere gesing gaan word. Die prediker, as liturg, behoort ook van die musikus inligting te $k r y$ oor die stemming wat ' $n$ bepaalde lied en melodie wil tuisbring sodat dit vooraf met die gemeente gedeel kan word. Ook behoort die prediker die stemming van sy preek met die musikus te bespreek sodat laasgenoemde hom/haar kan voorberei daarop. En waarom kan die musikus as musiekkenner nie sekere inligting oor die musiek self aan die gemeente mondelings deurgee voordat 'n lied gesing word nie?

\subsection{Bekend maak bemind}

Alleen wanneer die gemeente die psalms, hul inhoud, betekenis en die melodieë ken, sal daar weer werklik genot geput word uit die gebruik van hierdie kommunikasiemiddel met God in die erediens. Dit verg egter insette van al die betrokke partye, naamlik leraars, orreliste en gemeentelede. Die kerkkoor kan byvoorbeeld die gemeente voorgaan in die aanleer van die melodieë. Baie probleme en negatiewe gesindhede rakende die psalmberymings en melodieë kan deur goeie kommunikasie met die gemeente asook deur stelselmatige aanleer daarvan oorbrug word.

\subsection{Balans tussen sang en musiek}

Die sang en musiek in die gemeente weerspieël tot 'n sekere mate die meelewing van die lidmate aan die erediens. 'n Goeie balans tussen vokale en instrumentale musiek is baie stimulerend. Sodra die instrumentale musiek egter oorheers, word die gemeente van sy meelewing ontneem. Dit is veral die orrelis wat hierdie fyn aanvoeling moet hê of aanleer, maar die leraar kan ook in versigtige en sinvolle gesprek met die orrelis help om hierdie balans te handhaaf.

\subsection{Eenvoud en smaakvolheid}

'Terwyl die psalmberymings en melodieë tans weer hersien word, moet eenvoud en smaakvolheid 'n primêre rol speel ten opsigte van beide die taal en die musiek. Dit is hierdie twee basiese beginsels wat na my mening die sukses van psalmsang bewerkstellig.

\section{SLOT}

Vandag word daar nog voortdurende intensiewe psalmnavorsing gedoen vanuit verskillende benaderingshoeke ${ }^{36}$. Die kerk (en daarmee word in die eerste plek die leraars asook die orreliste as leidinggewende figure op hul onderskeie terreine in die gemeente bedoel) behoort meer hiervan kennis te neem sodat die resultate van 
die navorsing geïmplementeer kan word binne gemeenteverband. Die psalms is volkome God se Woord en die mens se antwoord. Die hoop kan maar net uitgespreek word dat die musikoloë, teoloë en taalkenners wat tans hierdie probleem probeer aanspreek saam die groot leemte sal kan vul deur sinvol gebruik te maak van die navorsingsresultate van al die betrokke vakgebiede. Indien daar'n gesindheidsverandering in gemeentes bewerkstellig kan word ten opsigte van psalmsang as kommunikasiemiddel tussen mens en God, sal die sangbelewenis 'n verdieping ondergaan en sal daar minder na dikwels oppervlakkige populêre melodieë en inhoude gegryp word soos wat tans gebeur.

\section{NOTAS:}

1 Referaat gelewer tydens die Johannesburg/Wes-Rand Streek-kongres van Die Suid-Afrikaanse Kerkorrelistevereniging op 12 September 1992 te Johannesburg.

2 Vergelyk G Von Rad, Theologie des Alten Testaments, Band 1. München ${ }^{2}$ 1958, 352-353; C Westermann, Theologie des Alten Testaments in Grundzügen, Göttingen 1978, 134-153; J J Burden, "Poëtiese tekste", in Woorde wat ver kom (Onder redaksie van F Deist \& W Vorster), Kaapstad 1986, 39; C W Burger, "Die prediking van die psalms", in Riglyne vir prediking oor die Psalms (Onder redaksie van C W Burger, B A Müller \& D J Smit), Kaapstad, 1988, 10.

3 Burger, Müller \& Smit, $a w, 10$.

4 J P M Van der Ploeg, Psalmen, Deel 1, Roermond 1971, 9.

5 Burger, Müller \& Smit, $a w, 9$.

6 J J Burden, Psalms 101-119, Kaapstad 1991, 13.

7 H-J Kraus, Psalmen, 1. Teilband, Neukirchen-Vluyn, 1972, xvii.

8 Van der Ploeg, $a w, 16$.

9 Kraus, $a w, 1972$, xxviii.

10 Kraus, $a w, 1972$, xxxvii-lvi.

11 Burden, $a w, 1986,39$.

12 Burden, $a w, 1986,40$.

13 A Sendrey, Music in Ancient Israel, London 1969, 240.

14 Vgl H-J Kraus, Theologie der Psalmen, Neukirchen-Vluyn 1979.

15 C Schmidt-Colinet, Die Musikinstrumente in der Kunst des Alten Orients: 
Archäologisch-philologische Studien, Bonn 1981, 30.

16 C Sachs, The rise of music in the Ancient World East and West, London 1944, 59.

17 Sendrey, $a w, 169$.

18 Sendrey, $a w, 169$.

19 Sendrey, $a w, 172$.

20 A Weiser, Introduction to the Old Testament, London 1972, 325.

21 Sendrey, $a w, 77$.

22 Sendrey, $a w, 172$.

23 Sendrey, $a w, 173$.

24 W Nowack, "Music and musical intruments", in The Jewish Encyclopedia, vol 9, New York/London 1905, 119.

$25 \quad$ P J van Dyk, "Music in Old Testament times", Old Testament Essays 4 (1991), 376.

26 Sendrey, $a w, 552$.

27 Sendrey, $a w, 190$.

28 Sendrey, $a w, 189,196-205$.

29 Sendrey, $a w, 198$.

30 Sendrey, $a w, 200$.

31 Sendrey, $a$ w, 201.

32 Sendrey, $a w, 204$.

33 W Mudde, "Kerkmuziek", in: Christelijke Encyclopedie, Band 4, Kampen 1959, 229.

34 Mudde, $a w, 229$.

35 Burger, Müller \& Smit, a w, 10.

36 J H Coetzee, "A survey of research on the Psalms of Lamentation", Old Testament Essays 5 (1992), 151-174. 